\title{
Management of left ventricular thrombus: a narrative review
}

\author{
Jose B. Cruz Rodriguez ${ }^{1}$, Kazue Okajima ${ }^{1} \wedge$, Barry H. Greenberg ${ }^{2} \wedge$ \\ ${ }^{1}$ Division of Cardiovascular Diseases, Texas Tech University Health Science Center, El Paso, TX, USA; ${ }^{2}$ Heart Failure/Cardiac Transplantation \\ Program, University of California, San Diego, CA, USA \\ Contributions: (I) Conception and design: All authors; (II) Administrative support: JB Cruz Rodriguez; (III) Provision of study materials or patients: \\ JB Cruz Rodriguez; (IV) Collection and assembly of data: All authors; (V) Data analysis and interpretation: All authors; (VI) Manuscript writing: All \\ authors; (VII) Final approval of manuscript: All authors. \\ Correspondence to: Jose B. Cruz Rodriguez, MD, MPH. Division of Cardiovascular Diseases, Texas Tech University Health Science Center, 4800 \\ Alberta Avenue, El Paso, TX 79905, USA. Email: Benjamin.cruz@ttuhsc.edu.
}

\begin{abstract}
Left ventricular thrombus (LVT) is a serious complication of acute myocardial infarction (MI) and also non-ischemic cardiomyopathies. We performed a narrative literature review, manual-search of reference lists of included articles and relevant reviews. Our literature review indicates that the incidence of LVT following acute MI has decreased, probably due to improvement in patient care as a result of better and earlier reperfusion techniques. Predictors of LVT include anterior MI, involvement of left ventricular (LV) apex (regardless of the coronary territory affected), LV akinesis or dyskinesis, reduced LV ejection fraction (LVEF), severe diastolic dysfunction and large infarct size. LVT is associated with increased risk of systemic embolism, stroke, cardiovascular events and death, and there is evidence that anticoagulant therapy for at least 3 months can reduce the risk of these events. Cardiac magnetic resonance (CMR) has the highest diagnostic accuracy for LVT, followed by echocardiography with the use of echocardiographic contrast agents (ECAs). Although current guidelines suggest use of vitamin $\mathrm{K}$ antagonist (VKA) for a minimum of 3 to 6 months, there is growing evidence of the benefits of direct acting oral anticoagulants in treatment of LVT. Embolic events appear to occur even after resolution of LVT suggesting that anticoagulant therapy needs to be considered for a longer period in some cases. Recommendations for the use of triple therapy in the presence of the LVT are mostly based on extrapolation from outcome data in patients with atrial fibrillation (AF) and MI. We conclude that the presence of LVT is more likely in patients with anterior STsegment elevation MI (STEMI) (involving the apex) and reduced ejection fraction (EF). LVT should be considered a marker of increased long-term thrombotic risk that may persist even after thrombus resolution. Ongoing clinical trials are expected to elucidate the best management strategies for patients with LVT.
\end{abstract}

Keywords: Left ventricular thrombus (LVT); thrombosis; apical thrombus; apixaban; warfarin; dabigatran; rivaroxaban

Submitted Dec 08, 2020. Accepted for publication Jan 25, 2021.

doi: 10.21037/atm-20-7839

View this article at: http://dx.doi.org/10.21037/atm-20-7839

\section{Introduction}

Left ventricular thrombus (LVT) is a serious complication of acute myocardial infarction (MI) and also of nonischemic cardiomyopathies (1). Epidemiologic data suggest the incidence of LVT to be as high as $15 \%$ in patients with ST-segment elevation MI (STEMI), up to $25 \%$ in patients experiencing an anterior MI (2) and between 2-36\% $(3,4)$ in patients with nonischemic cardiomyopathies. Regardless

^ ORCID: Jose B. Cruz Rodriguez, 0000-0002-2022-6141; Kazue Okajima, 0000-0002-3286-1361; Barry H. Greenberg, 0000-0002-66059385 . 
of the etiology, however, there is potential for cerebral or systemic embolization from LVT that increases the morbidity and mortality in patients with both ischemic and non-ischemic cardiomyopathies.

Given the scarcity of randomized clinical trials (RCTs) evaluating the optimal treatment regimen, duration and effects in the prevention or treatment of LVT, we performed a narrative literature review in order to examine available information about therapeutic options for patients with this condition. We searched the PubMed, Embase, Cochrane Central Register of Controlled Trials (CENTRAL), and Cumulative Index to Nursing and Allied Health Literature (CINAHL) databases through November 9th 2020, with no restrictions on language. Key words of left ventricular thrombus, apical thrombus, apixaban, warfarin, dabigatran and rivaroxaban were used in these searches. Large prospective studies, metanalysis and systematic reviews were included, although notably, there are few RCTs on the topic. Relevant references in the articles that were identified were then manually-searched. We present the following article in accordance with the Narrative Review reporting checklist (available at http://dx.doi.org/10.21037/atm-207839).

\section{Prevalence and risk factors}

Historically, the incidence of LVT following acute MI had been reported to be $20-40 \%$, and even $60 \%$ among patients with large anterior MI $(5,6)$. With the wide validation of thrombolytic therapy for MI in the 1980s, the incidence of LVT was reduced to $5-16 \%$, likely due to salvaging myocardium at risk and minimizing wall motion abnormalities $(7,8)$. Table 1 presents a chronological summary of studies discussing the prevalence of LVT.

STEMI patients have been reported to be more likely to have LVT compared to non-STEMIs (43.1\% vs. 5.0\%) (17). Once primary percutaneous coronary intervention (PCI) became the standard of care for STEMI (after the mid 1990's), the prevalence of LVT seems to be even smaller, with a cumulative incidence of $10 \%$ compared to $33 \%$ $(1,28)$. In a retrospective, single center study $(n=1,059)$ of STEMI patients treated with primary PCI, LVT was detected in $5 \%$ of the subjects. Patients with LVT were more likely to have lower left ventricular ejection fraction (LVEF) (47\% vs. 35\%, $\mathrm{P}<0.01)$, anterior MI ( $88 \%$ vs. $42 \%$, $\mathrm{P}<0.01$ ) and apical akinesis (irrespective of the vascular location of the MI). Use of IIb/IIIa inhibitor and symptoms to balloon time were of borderline statistical significance in predicting prevalence of LVT, possibly suggesting an association with larger infarcted territories (18). A smaller $(\mathrm{n}=92)$ study in patients who underwent primary PCI plus IIb/IIIa inhibitor use showed a prevalence of $4.3 \%$ (11). Similarly, another single center study $(\mathrm{n}=1,698)$ in STEMI patients where echocardiographic contrast agents (ECAs) were used in $76 \%$ of the cohort, reported a prevalence as low as $1.6 \%$ for LVT (21). Echocardiography was performed early after reperfusion, which could have missed later thrombi formation.

Early treatment with PCI is only one of the several ongoing changes in STEMI care compared to historical cohort. Other changes include more effective antiplatelet agents, reduced time to revascularization and newer generations of stents, all of which aim to minimize infarct size. The resultant wall motion abnormalities should then be expected to decrease the risk for $\operatorname{LVT}(29,30)$. A metanalysis (1) including 19 articles from 2000 to 2015 $(\mathrm{n}=10,076)$ in STEMI patients who underwent PCI showed a LVT incidence rate of $2.7 \%$ (95\% CI: $1.9-3.5 \%$ ). In selective analysis of those with anterior MI, the rate of LVT was $9.1 \%$ (95\% CI: $6.6-11.6 \%)$ which decreased to $7.5 \%$ in a sensitivity analysis of studies greater than 100 patients (31).

Across studies, described predictors of LVT are anterior $\mathrm{MI} /$ left anterior descending territory, involvement of left ventricular (LV) apex regardless of the coronary artery affected, akinesis or dyskinesis, reduced LVEF and large infarct size $(32,33)$. Presence of multivessel coronary artery disease and PCI of culprit lesion only compared to complete revascularization were not predictive of LVT in other reports (34). Moreover, severe diastolic dysfunction (restrictive LV filling pattern) has been associated with increased risk of LVT, measured either by mitral deceleration time $<130 \mathrm{~ms} \mathrm{(35)}$ or increased mitral E/A ratio $>2$ (36). Although moderate to severe mitral regurgitation after MI has been associated to LVT (37), this relationship was confounded by the extent of wall motion abnormalities and anterior location of the MI and mitral regurgitation was no longer significant after adjusting for these variables. Cardiac magnetic resonance (CMR) volumetric analyses have shown that larger LV volumes and impaired systolic function correlate with higher incidence of $\operatorname{LVT}(5,38)$. Furthermore, patients with LVT have been reported to have significantly higher C-reactive protein, fibrinogen, leukocytes and platelet levels than MI patients without LVT $(39,40)$. Rather than playing independent roles, the combination of these risk factors interact with each other to promote LVT. Figure 1 displays this relationship. 
Table 1 Clinical studies in diagnosis and prevalence of LVT

\begin{tabular}{|c|c|c|}
\hline $\begin{array}{l}\text { Author, year } \\
\text { (reference) }\end{array}$ & $\begin{array}{l}\text { Type of study } \\
\text { [number of patients] }\end{array}$ & Conclusion \\
\hline $\begin{array}{l}\text { Ezekowitz, } \\
1982(9)\end{array}$ & Prospective [53] & $\begin{array}{l}\text { Compared to surgical or autopsy confirmation, sensitivity of indium-111 platelet scintigraphy for LVT } \\
71 \% \text {, echocardiography } 77 \% \text {. Specificity of scintigraphy } 100 \% \text {, echocardiography } 93 \%\end{array}$ \\
\hline $\begin{array}{l}\text { Gottdiener, } \\
1983(3)\end{array}$ & Retrospective [123] & Prevalence of LVT was $36 \%$ in nonischemic cardiomyopathy, systemic emboli in $11 \%$ \\
\hline $\begin{array}{l}\text { Pizzetti, } \\
1996(7)\end{array}$ & Retrospective [418] & After thrombolysis treatment, $16 \%$ prevalence of LVT, $39 \%$ in those with anterior MI \\
\hline $\begin{array}{l}\text { Thanigaraj, } \\
1999 \text { (10) }\end{array}$ & Retrospective [409] & $\begin{array}{l}\text { Use of ECA increase diagnostic yield of LVT in } 79 \% \text { of patients with nondiagnostic non-contrast } \\
\text { images }\end{array}$ \\
\hline $\begin{array}{l}\text { Rehan, } \\
2006(11)\end{array}$ & Prospective [92] & After STEMI treated with PCI and glycoprotein IIb/IIla inhibitors, incidence of LVT was $4.3 \%$ \\
\hline $\begin{array}{l}\text { Kurisu, } \\
2011(12)\end{array}$ & Retrospective [95] & Prevalence of LVT was $5.3 \%$ in the setting of Takotsubo cardiomyopathy \\
\hline $\begin{array}{l}\text { Weinsaft, } \\
2008(13)\end{array}$ & Retrospective [784] & $\begin{array}{l}\text { Delayed enhancement-CMR detected thrombus in } 7 \% \text { and cine-CMR in } 4.7 \% \text { of patients with } \\
\text { ischemic cardiomyopathy }\end{array}$ \\
\hline $\begin{array}{l}\text { Weinsaft, } \\
2009(14)\end{array}$ & Retrospective [121] & $\begin{array}{l}\text { Contrast echo nearly doubled sensitivity ( } 61 \% \text { vs. } 33 \%) \text { and yielded improved accuracy }(92 \% \text { vs. } \\
82 \%) \text { versus non-contrast echo. Contrast echo and cine-CMR correlated well on the diagnosis of } \\
\text { thrombus }\end{array}$ \\
\hline $\begin{array}{l}\text { Gianstefani, } \\
2014(18)\end{array}$ & $\begin{array}{l}\text { Retrospective } \\
{[1,059]}\end{array}$ & $\begin{array}{l}\text { After STEMI treated with } \mathrm{PCI} \text {, prevalence of } \mathrm{LVT}=4 \% \text {. Apical akinesis noted in all LVT regardless of } \\
\text { the territory infarcted. No difference in mortality in patients treated with warfarin for 3-6 months }\end{array}$ \\
\hline $\begin{array}{l}\text { Wada, } \\
2014(19)\end{array}$ & Retrospective [392] & $\begin{array}{l}\text { Sensitivity and specificity of non-contrast echocardiography for detection of LVT were } 88 \% \text { and } \\
96 \% \text {, respectively, compared with } 100 \% \text { each with contrast echocardiography }\end{array}$ \\
\hline $\begin{array}{l}\text { Robinson, } \\
2016 \text { (1) }\end{array}$ & $\begin{array}{l}\text { Meta-analysis } \\
{[10,076]}\end{array}$ & After STEMI treated with $\mathrm{PCl}$, summary rate of LVT $=2.7 \%, 9.1 \%$ in those with anterior $\mathrm{MI}$ \\
\hline $\begin{array}{l}\text { Zeng, } \\
2016(20)\end{array}$ & Retrospective [24] & $\begin{array}{l}\text { lodine densities were significantly lower in the LVT than the LV cavity, whereas blood densities in the } \\
\text { two areas did not differ significantly }\end{array}$ \\
\hline $\begin{array}{l}\text { Mao, } \\
2018(21)\end{array}$ & $\begin{array}{l}\text { Retrospective } \\
{[1,698]}\end{array}$ & After STEMI treated with PCI, prevalence of LVT $=1.6 \%$ \\
\hline $\begin{array}{l}\text { Rowin, } \\
2017 \text { (22) }\end{array}$ & $\begin{array}{l}\text { Retrospective } \\
{[1,940]}\end{array}$ & $\begin{array}{l}\text { In patients with HCM, incidence of apical aneurysm of } 4.8 \% \text { and LVT was present in } 19.3 \% \text { of them, } \\
0.9 \% \text { of the entire cohort }\end{array}$ \\
\hline
\end{tabular}

Table 1 (continued) 
Table 1 (continued)

\begin{tabular}{|c|c|c|}
\hline $\begin{array}{l}\text { Author, year } \\
\text { (reference) }\end{array}$ & $\begin{array}{l}\text { Type of study } \\
\text { [number of patients] }\end{array}$ & Conclusion \\
\hline $\begin{array}{l}\text { Maron, } \\
2008(23)\end{array}$ & $\begin{array}{l}\text { Retrospective } \\
{[1,299]}\end{array}$ & $\begin{array}{l}\text { Among patients with } \mathrm{HCM} \text {, incidence of apical aneurysm of } 1.7 \% \text { and LVT was present in } 9.1 \% \text { of } \\
\text { them, } 0.2 \% \text { of the entire cohort }\end{array}$ \\
\hline $\begin{array}{l}\text { Kitkungvan, } \\
2018(24)\end{array}$ & Retrospective [121] & Prevalence of LVT was $7.4 \%$ in patients with chemotherapy-related LV dysfunction \\
\hline $\begin{array}{l}\text { Hamada, } \\
2019(26)\end{array}$ & Case series [5] & All presented patients with HCM had apical aneurysm, only 2 with outflow obstruction \\
\hline $\begin{array}{l}\text { Ding, } \\
2020 \text { (27) }\end{array}$ & $\begin{array}{l}\text { International } \\
\text { Registry }[1,676]\end{array}$ & Prevalence of LVT was 3.3\% in the International Takotsubo Registry \\
\hline
\end{tabular}

CMR, cardiac magnetic resonance; ECA, echocardiographic contrast agent; HCM, hypertrophic cardiomyopathy; LVT, left ventricular thrombus; MI, myocardial infarction; NSTEMI, non-ST elevation myocardial infarction; RCT, randomized clinical trial; STEMI, ST elevation myocardial infarction; TEE, transesophageal echocardiogram; TTE, transthoracic echocardiogram; VA-ECMO, veno-arterial extracorporeal membrane oxygenation.

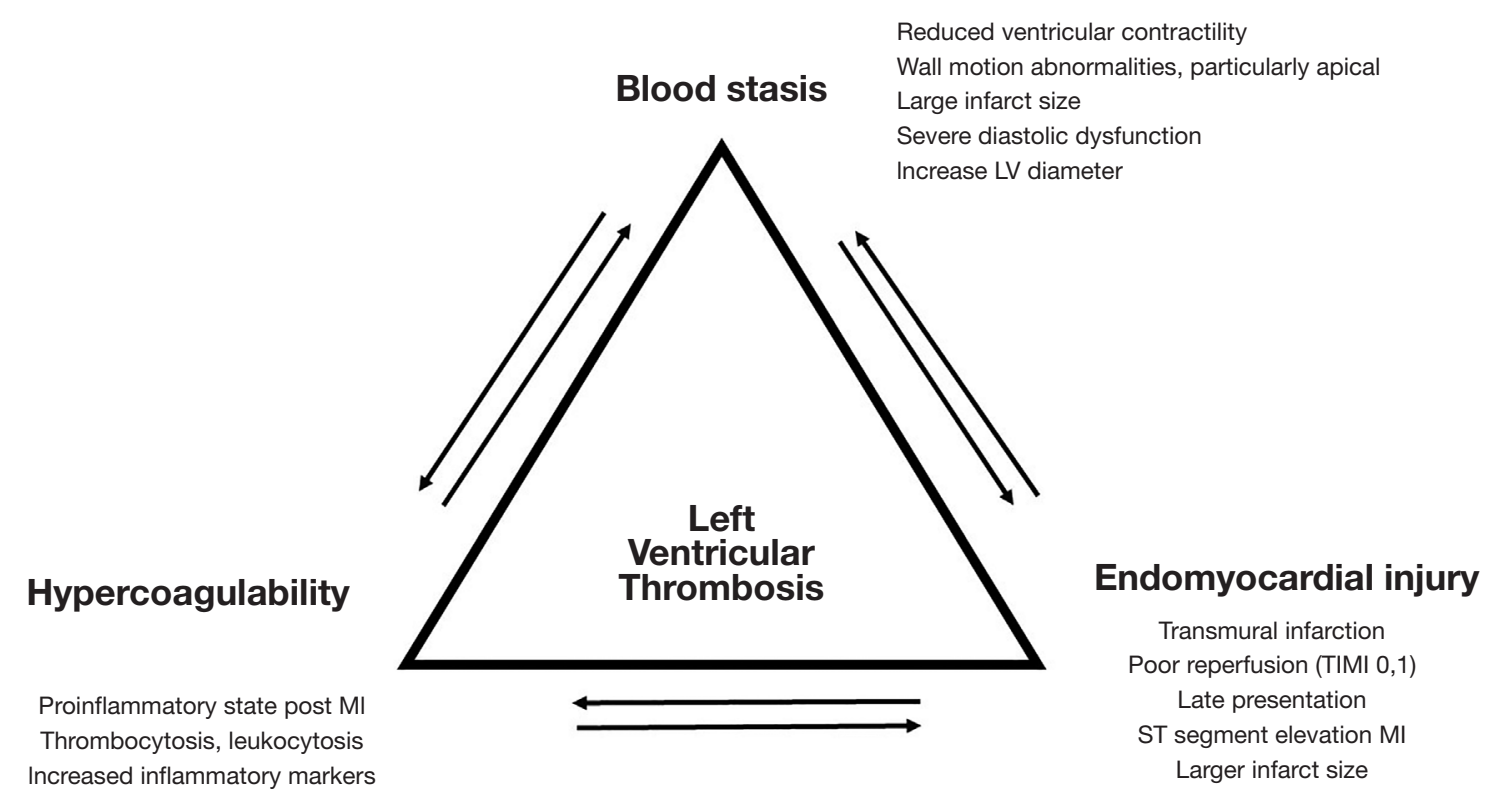

Figure 1 Thrombogenic mechanisms in LV thrombosis. LV, left ventricle; MI, myocardial infarction; TIMI, thrombolysis in MI.

Most reported series of LVT focus on ischemic cardiomyopathy, and there is a paucity of studies in patients with non-ischemic etiologies. This is compounded by small sample size of the available studies resulting in poor precision (wide confidence intervals) for incidence and prevalence determinations. Previous studies reported prevalence of LVT up to $36 \%$ in the setting of dilated cardiomyopathy $(3,9)$, with an incidence of $11 \%$ for embolic events. In the setting of dilated cardiomyopathy, presence of coronary artery disease (that was not considered to be the cause of the cardiac dysfunction) was not associated to the presence of thrombus nor systemic embolism (39). A secondary analysis from the WATCH trial $(n=1,343)$, multicentric prospective randomized trial for the use of 
warfarin and antiplatelets in patients with chronic dilated cardiomyopathy in sinus rhythm reported a prevalence of LVT of $2.1 \%$ (4). Factors associated significantly to LVT were younger age, lower ejection fraction $(\mathrm{EF})$, higher regional wall motion score, higher early diastolic filling velocity, shorter deceleration time, greater LV diastolic dimension and left atrium area.

In a cohort of patients $(n=121)$ with chemotherapyrelated severe $L V$ dysfunction (24), defined as LVEF $<30 \%$, the prevalence of LVT was $7.4 \%$. Factors associated with presence of LVT were restrictive filling pattern (OR: 18.13, 95\% CI: 4.17-78.89) and LVEF <20\% (OR: 36.30, 95\% CI: 7.35-179.25). Albeit significant, this report posed very wide confidence intervals due to the small number of thrombi detected. Cancer is known to induce a prothrombotic and hypercoagulable state $(41,42)$, and malignancies that have been shown to be particularly prothrombotic such as breast cancer (41), lymphoma (43) and leukemias (44) should increase the level of suspicion in these patients.

There are limited reports (45) and small case series of LVT in patients with stress-induced cardiomyopathy (Takotsubo). The reported incidence of LVT in this patient population is $3-5.3 \%$ (12). The largest cohort of patients with this condition, the International Takotsubo Registry, recorded a 3.3\% prevalence of LVT and embolism in the acute phase of the disease (27). Stress-induced cardiomyopathy usually presents with a larger LV apical aneurysm than anterior MI, but the lower incidence of $\mathrm{LV}$ apical thrombosis could be related to its transient nature and lack of endocardial damage compared to MI. On the other hand, if LVT develops in this setting, the rapid improvement in apical contraction seen in most cases could theoretically increase the risk of embolic events.

Reports of LVT in hypertrophic cardiomyopathy $(\mathrm{HCM})$ are scarce. In a case series $(\mathrm{n}=5)$ of patients with LVT and HCM (26), all had apical aneurysm, two had $\mathrm{LV}$ outflow obstruction, one atrial fibrillation (AF) and all had resolution of the LVT with anticoagulation [three with direct oral anticoagulants (DOACs) and two with warfarin]. In a large cohort of patients with HCM, reports from 2008 and then $2017(22,23)$ suggested incidence of apical aneurysm of $1.7-4.8 \%$, with LVT present in 9.1$19.3 \%$ of them $(0.2-0.9 \%$ of the entire cohort). There is contradictory data about the presence of mid-ventricular obstruction as the leading factor in the progression of $\mathrm{LV}$ apical aneurysm formation (46-48) and LVT formation.

LVT has also been occasionally described in amyloidosis (49), hypereosinophilic syndrome (50), and
Chagas' disease (51).

There is also limited data of LVT in patients requiring veno-arterial extracorporeal membrane oxygenation (VAECMO). A case series $(n=11)$, all of them due to ischemic cardiomyopathy complicated with cardiogenic shock, suggested a prevalence of $3.1 \%$ of the entire VA-ECMO experience of that center (25). Despite use of inotropic support to promote contractility and anticoagulation in the therapeutic range at the time of diagnosis, the mortality in this report of $100 \%$, highlights the seriousness of LVT in this patient population.

\section{Diagnosis}

Routine transthoracic echocardiography (TTE) after primary PCI-treated MI is recommended to assess biventricular function, valvulopathies, exclude postinfarction mechanical complications and evaluate for LVT (52).

Standard TTE is commonly used for screening, but it has low sensitivity for LVT detection, requiring the addition of ECA and/or use of CMR imaging (2). Despite its widespread use and even with the most advanced echocardiographic equipment, TTE can be technically challenging in patients with small intercostal spaces, large body size, chest deformities or lung disease (poor acoustic windows), leading to potential failure to detect subtle LVT findings. Intrinsic limitations of TTE reduce its diagnostic accuracy, particularly in small non-protruding mural thrombi, due to true apex foreshortening, limited near-field resolution or consequent artifacts (near-field clutter) and difficulty discriminating myocardium-thrombi interface.

Table 1 presents a chronological summary of studies discussing the diagnostic modalities used to detect LVT. Although transesophageal echocardiogram (TEE) has well established superiority for detection of atrial thrombi, its role for LVT is more limited. As many as $46 \%$ of patients have nonconclusive studies $(10,53)$ for LVT with this semiinvasive procedure. Techniques to improve the diagnostic image quality and improve blood-endocardial surface include harmonic imaging (54) and ECA $(54,55)$. The use of ECA has been reported to be cost effective (55) and increase the echocardiographic sensitivity for LVT detection from $33 \%$ to $100 \%$, and the specificity from $82 \%$ to $92 \%(14,19,29)$.

A single center study (5) in patients with ischemic heart disease $(n=361)$ evaluated the diagnostic accuracy of TTE, TEE and CMR with contrast enhancement for evaluation 
of LVT which was confirmed by surgical or post-mortem confirmation. The decision to use ECA was at the discretion of the echocardiographer in this survey. Thrombus was found to be apically located in $71 \%$ of the cases, associated with aneurysm in $77 \%$ of the cases. It has been suggested that the accuracy of TTE is as high as CMR when the request for the search of a thrombus is prespecified (34). Echocardiographic features can predict embolic potential and guide management of LVT as described in subsequent sections (56).

The superiority of CMR $(5,57,58)$ with gadolinium compared to other imaging modalities for detection of LVT is derived to the immediate strong enhancement of $\mathrm{LV}$ cavity, allowing detection of abnormal intraventricular structures, as well as the delayed-enhancement technique that allows visualization of LVT (black), commonly adjacent to scarred myocardium (bright or hyper-enhanced). On the other hand, CMR has a higher cost and is not widely available, even in developed countries. CMR had the highest diagnostic accuracy with sensitivity of $88 \%$ and specificity of $99 \%$, followed by TEE with $40 \%$ and $96 \%$ respectively, and TTE with $23 \%$ and $96 \%$, respectively (15).

CMR studies (13) have shown that patients with ischemic cardiomyopathy have a fivefold higher prevalence of LVT that patients with non-ischemic cardiomyopathy, even with similar LVEF. LVT was more likely to be found in areas with increased myocardial scarring, a parameter that can only be evaluated with delayed-enhancement CMR. Because of this reason, cine-only CMR could miss small intracavitary and mural thrombus.

There are few studies describing the use of cardiac computerized tomography (CT) for the detection of LVT. Historically, it was considered that CT scanning provides similar accuracy as TTE in detecting LVT, but does so at the expense of increased radiation exposure and requirement for iodine contrast use (59). Recent case reports have suggested that metabolically inert areas seen on positron emission tomography/CT (PET/CT), with corresponding homogeneous hypodensity in the $\mathrm{LV}$ cavity could suggest organized LVT (60), particularly in patients with limited echocardiographic windows (61). LVT are frequently crescent-shaped filling defects with broad based attachments, although pedunculated appearances have been described (62). Chronic thrombi may develop spotty calcifications, although this finding can also be seen in myxomas (63). CT characteristics of LVT include lower attenuation with a threshold of 65 Hounsfield units, providing a sensitivity and specificity of $94 \%$ and $97 \%$, respectively (16). It has been suggested that spectral CT dual-substance separation imaging and derived images of iodine- and blood-based densities are a feasible semiquantitative method to investigate LVT (20).

Although indium-111 platelet scintigraphy has been reported to be comparable to TTE for the diagnosis of LVT (40), it is an older technology with virtually no role in current clinical practice.

Irrespective of the imaging modality utilized, if LV function is found to be depressed, particularly with akinetic or dyskinetic segments, special attention should be placed on evaluating for LVT.

\section{Embolic risk and mortality}

The reported risk of embolic events from a LVT post-MI ranges from $6.1 \%$ to $86 \%$ and seems to be greatest in the first 3 months after MI $(5,58,64-66)$. In one report, the incidence of thromboembolism decreased from $22.3 \%$ in pre-PCI studies to $5.5 \%$ in post-PCI reports (28), likely due to increased myocardial salvage. Multiple studies have demonstrated that thrombus characteristics associated with systemic embolism include protrusion into the $\mathrm{LV}$ cavity (67), mobility independent of myocardium (68-70), patient age $>68$, thrombus area, length of the thrombi in the lumen, and LVT recurrence (71). On the other hand, thrombus described as laminated and calcified (bright and echo dense structures) are immobile, more likely to be chronic and less likely to embolize, although the risk is not zero and embolization for these laminar thrombi has been reported (72).

There is evidence to suggest that LVT should be considered a marker of increased long-term thrombotic risk that persists even after treatment and documented LVT resolution by imaging $(67,73)$. In a study with pathologic evaluation of the thrombus (3), among patients with documented recent embolic event, $67 \%$ had organized thrombus and $33 \%$ recent thrombus. Furthermore, up to $40 \%$ of embolic events can occur when thrombi are neither protuberant nor mobile $(5,71)$. Evaluation of acute ischemic strokes in patients with LVT (67) showed the median time from LVT diagnosis to cerebrovascular event was 20.5 days. Once again, $5.2 \%$ of patients had a stroke even with initial LVT resolution. The majority $(76.5 \%)$ of strokes were characterized as cardioembolic, followed by $14.7 \%$ as small vessel disease and $8.8 \%$ large artery atherosclerosis.

LVT is also associated to high rate of cardiovascular events. A contemporary cohort (74) showed that close to 
$50 \%$ of patients had a major cardiovascular event and $20 \%$ of patients died during follow up, a figure for mortality that is much higher than reported in STEMI patients without LVT.

\section{Cardioversion}

A small retrospective study $(\mathrm{n}=21)$ of patients with known $\mathrm{LV}$ apical thrombus requiring cardioversion ( $\mathrm{AF}$ in $38 \%$ and ventricular tachycardia in $62 \%$ ) reported no clinically apparent embolic events after cardioversion, despite only $81 \%$ of patients been anticoagulated beforehand (75). Nonetheless, most of the LV thrombi were described as laminated $(71 \%)$ and none of the patients had mobile thrombi, which theoretically pose the highest risk. A small case series $(n=8)$ of patients undergoing VT ablation (76) with documented LVT (all mural and laminated) showed only one ischemic stroke on post-procedure day 9 , in a patient with confirmed left atrial appendage (LAA) thrombus by TEE. All the patients underwent multiple intraprocedural cardioversion, suggestive the relative safety of cardioversion in the setting of laminated LVT.

\section{Prevention}

More effective revascularization strategies may reduce LVT formation in patients experiencing a MI, but LVT remains as a common complication of STEMI in the modern era. Along with resulting ischemic cardiomyopathy, LVT might be one of the predominant features affecting management and prognosis post PCI (32). Interestingly, thrombolysis in MI (TIMI) flow pre-PCI has been associated with LVT, but not TIMI flow post-PCI (18). Table 2 presents a chronological summary of studies involving prophylaxis and treatment of LVT.

In the thrombolytic era, a randomized trial (82) of dalteparin $150 \mathrm{IU} / \mathrm{kg}$ every 12 hours for 9 days, significantly reduced LVT formation in patients with anterior MI, although with increased risk of hemorrhagic complications (both major and minor). The short in-hospital data in this report limits the capacity to extrapolate its effectiveness as an outpatient regimen. Similar findings were reported with $12,500 \mathrm{U}$ of subcutaneous heparin (78) until discharge, but contradictory results were reported as well in a small $(n=30)$ RCT (77). A subsequent randomized trial (79) compared subcutaneous heparin high dose $(12,500 \mathrm{U}$ twice a day) with low doses (5,000 units twice a day) for 10 days after anterior MI, showing that the high dose was more effective without incremental bleeding risk.

With current standard of care of PCI and dual antiplatelet therapy (DAPT) after MI, small pilot randomized trial $(\mathrm{n}=60)$ in patients with anterior MI with $\mathrm{Q}$ waves and $\mathrm{EF}$ $\leq 40 \%$ showed that preventive full therapeutic dose of enoxaparin $(1 \mathrm{mg} / \mathrm{kg}$ twice a day, maximum dose $100 \mathrm{mg})$ for 30 days (85) had similar bleeding and thromboembolic events compared to anticoagulation with warfarin. More patients had probable mural thrombus at 3.5 months with enoxaparin, albeit the difference was not statistically significant.

A retrospective cohort (84) of 460 patients with apical akinesis or dyskinesis after STEMI on TTE showed that patients who received DAPT plus warfarin therapy experienced a net increase in adverse clinical events (allcause mortality, strokes, reinfarction and major bleeding) at 180 days. A single center retrospective study (88), suggested that ticagrelor based DAPT after anterior STEMI $(n=641)$ was associated with lower incidence of LVT when compared to clopidogrel (OR: 0.5, 95\% CI: 0.29-0.86).

Current guidelines $(52,93)$ suggest considering short courses ( 3 months) of anticoagulation in patients with large anterior wall MI, or anterior-apical akinesis (85) as a class $\mathrm{IIb}$, level of evidence (LOE) C recommendation.

\section{Treatment}

\section{Vitamin K antagonist (VKA)}

European and United State guidelines recommend as a class IIa, LOE C, treatment of LVT with VKAs for a minimum of 3 to 6 months, with duration individualized to bleeding risk $(52,94)$ with a target international normalized ratio (INR) of 2.5 (range, 2-3). Repeat imaging is suggested at the end of the treatment period to evaluate resolution of LVT as a class IIa, LOE C recommendation (52).

Lattuca et al., observed a significant decrease in risk of major cardiovascular events with anticoagulation for more than 3 months (48\% decrease) and LVEF $\geq 35 \%$ (54\% decrease).

The prothrombotic effect of VKA during the start of therapy warrants their coadministration with parenteral anticoagulation initially (81). A small prospective study $(\mathrm{n}=26)$ showed that enoxaparin $100 \mathrm{IU} / \mathrm{kg}$ twice a day, followed by fluindione treatment decreased thrombus size and resulted in resolution of thrombi in $73 \%$ of the patients, suggesting that this therapy may be as effective as unfractionated heparin (83) at 3 weeks. 
Table 2 Clinical studies in prevention and treatment of LVT

\begin{tabular}{|c|c|c|}
\hline $\begin{array}{l}\text { Author, year } \\
\text { (reference) }\end{array}$ & $\begin{array}{l}\text { Type of study } \\
\text { [number of patients] }\end{array}$ & Conclusion \\
\hline $\begin{array}{l}\text { Arvan, } \\
1987(77)\end{array}$ & $\mathrm{RCT}[30]$ & $\begin{array}{l}\text { No difference in LVT incidence after acute anterior MI with the use of heparin infusion, partial } \\
\text { thromboplastin time }>60 \text { seconds }\end{array}$ \\
\hline $\begin{array}{l}\text { Tavazzi, } \\
1989(78)\end{array}$ & $\mathrm{RCT}[711]$ & After acute anterior MI, 12,500 U of subcutaneous heparin reduced LVT incidence and mortality \\
\hline $\begin{array}{l}\text { Kouvaras, } \\
1990(80)\end{array}$ & Prospective [60] & High-dose aspirin was noninferior to warfarin for LVT resolution after 3 months \\
\hline $\begin{array}{l}\text { Kontny, } \\
1993(81)\end{array}$ & Prospective [229] & $\begin{array}{l}\text { High-dose heparin prevented LVT irrespective of warfarin therapy after acute anterior MI. Warfarin } \\
\text { therapy without heparin was associated with higher rates of LVT }\end{array}$ \\
\hline $\begin{array}{l}\text { Le May, } \\
2015(84)\end{array}$ & Retrospective [460] & $\begin{array}{l}\text { In patients with apical akinesis or dyskinesis, prophylactic use of warfarin increases net adverse } \\
\text { events (all-cause mortality, strokes, reinfarction and major bleeding) }\end{array}$ \\
\hline $\begin{array}{l}\text { White, } \\
2015(85)\end{array}$ & $\mathrm{RCT}[60]$ & $\begin{array}{l}\text { Enoxaparin for } 30 \text { days post MI shortened hospitalization and lowered cost of care compared to } \\
\text { warfarin, with no statistical difference among the groups of LVT at } 3 \text { months }\end{array}$ \\
\hline $\begin{array}{l}\text { Smetana, } \\
2017(86)\end{array}$ & Case series [10] & $\begin{array}{l}\text { Patients with LVT treated with rivaroxaban and apixaban showed complete thrombus resolution in } \\
8 \text { patients, with only one bleeding event }\end{array}$ \\
\hline $\begin{array}{l}\text { Robinson, } \\
2018(87)\end{array}$ & Retrospective [98] & DOAC-treated patients (mostly apixaban) had similar SSE-free survival \\
\hline $\begin{array}{l}\text { Lattuca, } \\
2020(74)\end{array}$ & Retrospective [159] & $\begin{array}{l}\text { Anticoagulation therapy }>3 \text { months was independently associated with less MACE (HR: } 0.42 ; 95 \% \\
\mathrm{Cl}: 0.20-0.88 ; \mathrm{P}=0.021) \text {. Reduced risk of mortality was observed among patients with total LVT } \\
\text { regression }(15.2 \% \text { vs. } 25.0 \% \text {; HR: } 0.48 ; \mathrm{P}=0.039) \text {, with higher bleeding rates }\end{array}$ \\
\hline $\begin{array}{l}\text { Robinson, } \\
2020 \text { (73) }\end{array}$ & Retrospective [514] & $\begin{array}{l}\text { Anticoagulation with DOAC vs. warfarin had higher rates of SSE (adjusted HR: } 2.64,95 \% \mathrm{Cl} \text { : } \\
1.28-5.43, \mathrm{P}=0.01 \text { ) }\end{array}$ \\
\hline $\begin{array}{l}\text { Guddeti, } \\
2020(90)\end{array}$ & Retrospective [99] & $\begin{array}{l}\text { Resolution of LVT, rates of stroke and bleeding were not statistically different between VKA and } \\
\text { DOAC }\end{array}$ \\
\hline $\begin{array}{l}\text { lqbal, } \\
2020(91)\end{array}$ & Retrospective [84] & $\begin{array}{l}\text { No statistically significant differences between VKA and DOAC in rates of LVT resolution ( } 76 \% \text { vs. } \\
65 \%) \text {, SSE ( } 2 \% \text { vs. } 0 \%) \text {, or clinically significant bleeding (10\% vs. } 0 \%)\end{array}$ \\
\hline Ali, 2020 (92) & Retrospective [110] & $\begin{array}{l}\text { Treatment with DOACs was associated with lower } 1 \text {-year risk of stroke ( } 12 \% \text { vs. } 6 \%, P=0.33) \text {, } \\
\text { although no difference found in ischemic stroke or thrombus resolution) }\end{array}$ \\
\hline
\end{tabular}

BID, every 12 hours; DOAC, direct oral anticoagulant; LVT, left ventricular thrombus; MACE, major adverse cardiovascular event; MI, myocardial infarction; NSTEMI, non-ST elevation myocardial infarction; RCT, randomized clinical trial; SSE, stroke or systemic embolism; STEMI, ST elevation myocardial infarction; VKA, vitamin K antagonist. 
Resolution of LVT has been reported with VKA (32), usually in addition to DAPT. In a small trial $(n=60)$, patients with LVT were randomized to aspirin $650 \mathrm{mg}$ daily, warfarin or placebo, finding that high-dose aspirin was noninferior to warfarin for LVT resolution after 3 months (80). Maniwa et al. showed that after 5.4 years of anticoagulation (median duration 34 months) patients with inadequate anticoagulation (time in therapeutic range $<50 \%)$ were more likely to develop systemic embolism, without difference in major bleeding events. Of interest, in this report the target INR range in this cohort was 1.6-2.6, according to the Japanese guideline of therapy for AF for elderly population (95).

If LVT recurs after resolution, longer-term anticoagulation could be considered (28). The recurrence rate after 6 months of anticoagulation has been reported as high as $18.5 \%$ (96). Moreover, after treatment with VKA, reduced mortality was observed in patients with total LVT regression whereas an increased major bleeding risk was observed among patients with persistent LVT (74).

\section{Direct oral anticoagulants}

DOACs are attractive alternatives for warfarin because of their potential efficacy and safety even though there is no randomized controlled trial that proves the effect of DOACs in LVT (97). The growing enthusiasm about DOACs is based on their ease of administration, lack of requirement for INR monitoring or dietary restrictions and overall improvement in quality of life (98).

The original indication for developing DOACs was anticoagulation for $\mathrm{AF}$, a condition with pathophysiologic and therapeutic differences compared to LVT. In AF, anticoagulation used is meant to prevent thrombus formation in the LAA in addition to promote dissolution of existing thrombi. The primary thrombogenic mechanism in $\mathrm{AF}$ is stasis, associated with low LAA emptying velocities. In LVT, the use of anticoagulation is focused on dissolution of existing thrombi. In this setting, thrombogenic mechanisms include stasis, hypercoagulability and endocardial changes (33) as depicted in Figure 1. These differences in pathophysiology could explain the differences in response to anticoagulation, and choice of the optimal agent. In patients with existing LAA thrombi, treatment with rivaroxaban resolved $41.5 \%$ of thrombus (99), although this report lacked warfarin control group.

Multiple case reports, case series $(86,100,101)$ and small single center retrospective studies $(\mathrm{n}<140)$ have reported similar efficacy between DOAC and VKA $(87,89,90$, 102-104) in LVT, although all of them had very few embolic events with short follow up. Anecdotally, in patients with persistent LVT after DOAC therapy, resolution of the LVT was seen in all patients after switching to VKA, with a higher INR goal of 3-4 (87). Furthermore, regarding safety, bleeding events and strokes comparable between the two groups (90). A case series of 10 patients with LVT treated with rivaroxaban and apixaban showed complete thrombus resolution in 8 patients, with only one bleeding event (86).

On the other hand, a larger multicenter retrospective cohort study $(\mathrm{n}=514)$, showed that DOAC treatment (43.9\% of total cohort, distributed as $76.2 \%$ apixaban, $24.9 \%$ rivaroxaban, $4.9 \%$ dabigatran) had an increased risk of stroke or systemic embolism at a median of 351 days of follow up (73). This finding was robust to sensitivity analysis including limiting to those with effective anticoagulation for only 3 months and restricting to 1 year of follow up. Authors did not evaluate bleeding complications in the groups, a theoretical advantage for DOACs. A more recent single center study $(\mathrm{n}=110)$ of patients with LVT showed a lower 1-year risk of any stroke with DOACs as compared to warfarin $(12 \%$ vs. $6 \%, \mathrm{P}=0.33)$, although no statistical difference was found in ischemic stroke or rate of thrombus resolution between warfarin and DOACs (92).

In another contemporary cohort $(\mathrm{n}=159)$, median duration of anticoagulation therapy was 508 days, $35 \%$ of patients were on anticoagulation and DAPT (74). After multivariate adjustment, factors associated with total LVT regression were non-ischemic cardiomyopathy (HR: $2.74 ; 95 \%$ CI: 1.43 to $5.26 ; \mathrm{P}<0.01$ ) and a smaller baseline thrombus area (HR: 0.66 ; $95 \%$ CI: 0.45 to 0.96 ; $\mathrm{P}=0.03)$. Recurrent LVT formation or increased size was associated with poor treatment adherence, chronic renal failure or prothrombotic conditions such as active cancer, inflammatory or hematological diseases. Although theoretically, LVT regression could be partially explained by thrombus embolization, this study did not find a significant difference in embolic complications between patients with or without LVT regression. Similar cohorts have reported that DOACs are likely to be as effective and safe as VKA (90), including no difference in resolution of stroke, other embolism, bleeding, rehospitalization and allcause mortality.

As an alternative to VKA therapy for the prevention of recurrent stroke, the 2014 American Heart Association/ 
American Stroke Association guidelines (105) introduced a new recommendation to consider treatment for 3 months with a low-molecular weight heparin, dabigatran, rivaroxaban, or apixaban in patients with ischemic stroke or transient ischemic attack in the setting of acute MI associated with LVT formation or anterior or apical wallmotion abnormalities with a LVEF $<40 \%$ who are intolerant to VKA therapy because of non-hemorrhagic adverse events (class IIb; LOE C).

\section{Surgical thrombectomy}

Surgical removal of the LVT is an option for patients with high embolic risk undergoing other open-heart surgery or at the time of transition from peripheral to central VA-ECMO configuration (106). The high morbidity and mortality of this approach outweigh the benefits of performing surgery solely for the indication of LVT (51).

\section{Triple therapy}

As many patients with LVT have an indication for DAPT, concern arises about increase bleeding risk with the addition of anticoagulation. Most studies comparing outcomes between triple therapy and DAPT typically included patients with different indications for anticoagulation, most commonly AF. Multiple studies have shown increase in bleeding events with prolonged triple antithrombotic therapy (107-109), although short them ( $<1$ month) did not find increase in bleeding complications (110).

In patients with STEMI-related LVT, a single center study $(\mathrm{n}=616)$ with a mean duration of triple therapy of 6.4 months reported a $2.5 \%$ risk of cardioembolic event and $18.5 \%$ risk of bleeding event (111).

Studies in the use of DOACs after MI, such as the Prevention of Bleeding in Patients with Atrial Fibrillation Undergoing PCI (PIONEER-AF PCI) (112), Dual Antithrombotic Therapy with Dabigatran after PCI in Atrial Fibrillation (REDUAL-PCI) (113) or Antithrombotic Therapy after Acute Coronary Syndrome or PCI in Atrial Fibrillation (AUGUSTUS) (114), that evaluated different combinations of DOAC and antiplatelet agents after PCI all in the setting of AF, suggest safety of the triple therapy. On the other hand, as explained above, the different pathophysiology of AF-related thrombosis contrasted to LVT could limit the extrapolation of these type of studies into LVT treatment.

\section{Future directions}

There is an important unmet need for adequately powered RCTs to address the many questions in the management of LVT. The evidence for recommendations for optimal anticoagulation regimens, combination with antiplatelets in the setting of MI, length of therapy, treatment in those with persistent LVT (chronic, "endotheliazed" thrombus), triple therapy in the setting of LVT and use of DOACs is still limited and in many cases anecdotal.

The information from ongoing clinical trials should provide information that will be pivotal for the management of LVT. In one trial (NCT01556659) patients will be randomized to VKA plus DAPT or DAPT alone in patients with PCI-treated STEMI and confirmed LVT. The EARLYmyo-LVT (NCT03786757) will evaluate the therapeutic efficacy and safety of low dose rivaroxaban (2.5 mg BID for 24 weeks) in the prevention of postSTEMI LVT. The EARLY-MYO-LVT (NCT03764241) will be a prospective, multi-center and randomized trial designed to investigate the efficacy and safety of rivaroxaban (15 mg daily) versus warfarin (goal INR: 2-2.5) in the treatment of post-STEMI LVT, on a background of DAPT (aspirin and clopidogrel) for 3-6 months (115).

\section{Summary}

LVT is more prevalent in patients with anterior STEMI (involving the apex) and reduced EF. LVT is associated with higher risk of cardiovascular events and death, and evidence suggests anticoagulation therapy for at least 3 months reduces this risk. LVT should be considered a marker of increased long-term thrombotic risk that may persist even after thrombus resolution. Ongoing clinical trials are expected to elucidate the best management strategies for patients with LVT.

\section{Acknowledgments}

Authors acknowledge Dr. Anoop Ayyappan for his comments on the section of cardiac CT for diagnosis of LVT.

Funding: None.

\section{Footnote}

Provenance and Peer Review: This article was commissioned by the editorial office, Annals of Translational Medicine for 
the series "Heart Failure Update and Advances in 2021". The article has undergone external peer review.

Reporting Checklist: The authors have completed the Narrative Review reporting checklist. Available at http:// dx.doi.org/10.21037/atm-20-7839

Conflicts of Interest: The authors have completed the ICMJE uniform disclosure form (available at http://dx.doi. org/10.21037/atm-20-7839). The series "Heart Failure Update and Advances in 2021" was commissioned by the editorial office without any funding or sponsorship. JBCR served as the unpaid Guest Editor of the series. The authors have no other conflicts of interest to declare.

Ethical Statement: The authors are accountable for all aspects of the work in ensuring that questions related to the accuracy or integrity of any part of the work are appropriately investigated and resolved.

Open Access Statement: This is an Open Access article distributed in accordance with the Creative Commons Attribution-NonCommercial-NoDerivs 4.0 International License (CC BY-NC-ND 4.0), which permits the noncommercial replication and distribution of the article with the strict proviso that no changes or edits are made and the original work is properly cited (including links to both the formal publication through the relevant DOI and the license). See: https://creativecommons.org/licenses/by-nc-nd/4.0/.

\section{References}

1. Robinson AA, Jain A, Gentry M, et al. Left ventricular thrombi after STEMI in the primary PCI era: a systematic review and meta-analysis. Int J Cardiol 2016;221:554-9.

2. McCarthy CP, Vaduganathan M, McCarthy KJ, et al. Left ventricular thrombus after acute myocardial infarction: screening, prevention, and treatment. JAMA Cardiolo 2018;3:642-9.

3. Gottdiener JS, Gay JA, VanVoorhees L, et al. Frequency and embolic potential of left ventricular thrombus in dilated cardiomyopathy: assessment by 2 -dimensional echocardiography. Am J Cardiol 1983;52:1281-5.

4. Gottdiener JS, Massie B, Ammons SB, et al. Prevalence of left ventricular thrombus in dilated cardiomyopathy: the WATCH trial. J Am J Cardiol 2003;41:202.

5. Srichai MB, Junor C, Rodriguez LL, et al. Clinical, imaging, and pathological characteristics of left ventricular thrombus: a comparison of contrast-enhanced magnetic resonance imaging, transthoracic echocardiography, and transesophageal echocardiography with surgical or pathological validation. Am Heart J 2006;152:75-84.

6. Keeley EC, Hillis LD. Left ventricular mural thrombus after acute myocardial infarction. Clin Cardiol 1996;19:83-6.

7. Pizzetti G, Belotti G, Margonato A, et al. Thrombolytic therapy reduces the incidence of left ventricular thrombus formation in acute anterior myocardial infarction.

Relationship to vessel patency and infarct size. Eur Heart J 1996;17:421-8.

8. Bhatnagar SK, Al-Yusuf AR. Effects of intravenous recombinant tissue-type plasminogen activator therapy on the incidence and associations of left ventricular thrombus in patients with a first acute $\mathrm{Q}$ wave anterior myocardial infarction. Am Heart J 1991;122:1251-6.

9. Ezekowitz MD, Wilson DA, Smith EO, et al. Comparison of indium-111 platelet scintigraphy and two-dimensional echocardiography in the diagnosis of left ventricular thrombi. N Engl J Med 1982;306:1509-13.

10. Thanigaraj S, Schechtman KB, Perez JE. Improved echocardiographic delineation of left ventricular thrombus with the use of intravenous second-generation contrast image enhancement. J Am Soc Echocardiogr 1999;12:1022-6.

11. Rehan A, Kanwar M, Rosman H. Incidence of post myocardial infarction left ventricular thrombus formation in the era of primary percutaneous intervention and glycoprotein IIb/IIIa inhibitors. A prospective observational study. Cardiovasc Ultrasound 2006;4:20.

12. Kurisu S, Inoue I, Kawagoe T, et al. Incidence and treatment of left ventricular apical thrombosis in Takotsubo cardiomyopathy. Int J Cardiol 2011;146:e58-60.

13. Weinsaft JW, Kim HW, Shah DJ, et al. Detection of left ventricular thrombus by delayed-enhancement cardiovascular magnetic resonance prevalence and markers in patients with systolic dysfunction. J Am Coll Cardiol 2008;52:148-57.

14. Weinsaft JW, Kim RJ, Ross M, et al. Contrast-enhanced anatomic imaging as compared to contrast-enhanced tissue characterization for detection of left ventricular thrombus. JACC Cardiovasc Imaging 2009;2:969-79.

15. Delewi R, Nijveldt R, Hirsch A, et al. Left ventricular thrombus formation after acute myocardial infarction as assessed by cardiovascular magnetic resonance imaging. Eur J Radiol 2012;81:3900-4.

16. Bittencourt MS, Achenbach S, Marwan M, et al. Left 
ventricular thrombus attenuation characterization in cardiac computed tomography angiography. J Cardiovasc Comput Tomogr 2012;6:121-6.

17. Mir JU, Raheel Jahangir J, Asfandyar Q, et al. Left ventricular thrombus in patients with acute anterior wall myocardial infarction. J Ayub Med Coll Abbottabad 2014;26:491-5.

18. Gianstefani S, Douri A, Delithanasis I, et al. Incidence and predictors of early left ventricular thrombus after STelevation myocardial infarction in the contemporary era of primary percutaneous coronary intervention. Am J Cardiol 2014;113:1111-6.

19. Wada H, Yasu T, Sakakura K, et al. Contrast echocardiography for the diagnosis of left ventricular thrombus in anterior myocardial infarction. Heart Vessels 2014;29:308-12.

20. Zeng H, Zhang MC, He YQ, et al. Application of spectral computed tomography dual-substance separation technology for diagnosing left ventricular thrombus. J Int Med Res 2016;44:54-66.

21. Mao TF, Bajwa A, Muskula P, et al. Incidence of left ventricular thrombus in patients with acute ST-segment elevation myocardial infarction treated with percutaneous coronary intervention. Am J Cardiol 2018;121:27-31.

22. Rowin EJ, Maron BJ, Haas TS, et al. Hypertrophic cardiomyopathy with left ventricular apical aneurysm. J Am Coll Cardiol 2017;69:761-73.

23. Maron MS, Finley JJ, Bos JM, et al. Prevalence, clinical significance, and natural history of left ventricular apical aneurysms in hypertrophic cardiomyopathy. Circulation 2008;118:1541-9.

24. Kitkungvan D, Yusuf SW, Moudgil R, et al. Echocardiographic measures associated with the presence of left ventricular thrombus in patients with chemotherapyrelated cardiac dysfunction. Echocardiography 2018;35:1512-8.

25. Weber C, Deppe AC, Sabashnikov A, et al. Left ventricular thrombus formation in patients undergoing femoral venoarterial extracorporeal membrane oxygenation. Perfusion 2018;33:283-8.

26. Hamada M. Left ventricular thrombus in hypertrophic cardiomyopathy. Intern Med 2019;58:465-7.

27. Ding KJ, Cammann VL, Szawan KA, et al. Intraventricular thrombus formation and embolism in Takotsubo syndrome: insights from the International Takotsubo Registry. Arterioscler Thromb Vasc Biol 2020;40:279-87.

28. Habash F, Vallurupalli S. Challenges in management of left ventricular thrombus. Ther Adv Cardiovasc Dis
2017;11:203-13.

29. Menees DS, Peterson ED, Wang Y, et al. Door-to-balloon time and mortality among patients undergoing primary PCI. N Engl J Med 2013;369:901-9.

30. Sabaté M, Räber L, Heg D, et al. Comparison of newergeneration drug-eluting with bare-metal stents in patients with acute ST-segment elevation myocardial infarction: a pooled analysis of the EXAMINATION (clinical Evaluation of the Xience-V stent in Acute Myocardial INfArcTION) and COMFORTABLE-AMI (Comparison of Biolimus Eluted From an Erodible Stent Coating With Bare Metal Stents in Acute ST-Elevation Myocardial Infarction) trials. JACC Cardiovasc Interv 2014;7:55-63.

31. French JK, Hellkamp AS, Armstrong PW, et al. Mechanical complications after percutaneous coronary intervention in ST-elevation myocardial infarction (from APEX-AMI). Am J Cardiol 2010;105:59-63.

32. Delewi R, Zijlstra F, Piek JJ. Left ventricular thrombus formation after acute myocardial infarction. Heart 2012;98:1743-9.

33. Meurin P, Carreira VB, Dumaine R, et al. Incidence, diagnostic methods, and evolution of left ventricular thrombus in patients with anterior myocardial infarction and low left ventricular ejection fraction: a prospective multicenter study. Am Heart J 2015;170:256-62.

34. Khaled S, Hachicha Z, Elkhateeb O. Left ventricular thrombus in myocardial infarction after successful primary percutaneous coronary intervention: prevalence and predictors - a middle eastern single-centre experience. CJC Open 2020;2:104-10.

35. Celik S, Baykan M, Erdol C, et al. Doppler derived mitral deceleration time as an early predictor of left ventricular thrombus after first anterior acute myocardial infarction. Am Heart J 2000;140:772-6.

36. Yilmaz R, Celik S, Baykan M, et al. Assessment of mitral annular velocities by Doppler tissue imaging in predicting left ventricular thrombus formation after first anterior acute myocardial infarction. J Am Soc Echocardiogr 2005;18:632-7.

37. Ascione L, Antonini-Canterin F, Macor F, et al. Relation between early mitral regurgitation and left ventricular thrombus formation after acute myocardial infarction: results of the GISSI-3 echo substudy. Heart 2002;88:131-6.

38. Sharma ND, McCullough PA, Philbin EF, et al. Left ventricular thrombus and subsequent thromboembolism in patients with severe systolic dysfunction. Chest 2000;117:314-20. 
39. Acar Z, Ziyrek M, Korkmaz L. Mean platelet volume at admission is a determinant of left ventricular thrombus formation after primary percutaneous coronary intervention for first anterior wall myocardial infarction. Acta Cardiol 2014;69:603-9.

40. Shacham Y, Leshem-Rubinow E, Ben Assa E, et al. Comparison of C-reactive protein and fibrinogen levels in patients having anterior wall ST-Segment elevation myocardial infarction with versus without left ventricular thrombus (from a primary percutaneous coronary intervention cohort). Am J Cardiol 2013;112:57-60.

41. Schmitt M, Kuhn W, Harbeck N, et al. Thrombophilic state in breast cancer. Semin Thromb Hemost 1999;25:157-66.

42. Lip GY, Chin BS, Blann AD. Cancer and the prothrombotic state. Lancet Oncol 2002;3:27-34.

43. Wada H, Sase T, Yamaguchi M. Hypercoagulant states in malignant lymphoma. Exp Oncol 2005;27:179-85.

44. Del Principe MI, Del Principe D, Venditti A. Thrombosis in adult patients with acute leukemia. Curr Opin Oncol 2017;29:448-54.

45. Kurisu S, Inoue I, Kawagoe T, et al. Left ventricular apical thrombus formation in a patient with suspected tako-tsubo-like left ventricular dysfunction. Circ J 2003;67:556-8.

46. Holloway CJ, Betts TR, Neubauer S, et al. Hypertrophic cardiomyopathy complicated by large apical aneurysm and thrombus, presenting as ventricular tachycardia. J Am Coll Cardiol 2010;56:1961.

47. Fighali S, Krajcer Z, Edelman S, et al. Progression of hypertrophic cardiomyopathy into a hypokinetic left ventricle: higher incidence in patients with midventricular obstruction. J Am Coll Cardiol 1987;9:288-94.

48. Hamada M, Shigematsu Y, Ohshima K, et al. Diagnostic usefulness of carotid pulse tracing in patients with hypertrophic obstructive cardiomyopathy due to midventricular obstruction: a comparison with idiopathic hypertrophic subaortic stenosis. Chest 2003;124:1275-83.

49. Feng D, Syed IS, Martinez M, et al. Intracardiac thrombosis and anticoagulation therapy in cardiac amyloidosis. Circulation 2009;119:2490-7.

50. Kleinfeldt T, Nienaber CA, Kische S, et al. Cardiac manifestation of the hypereosinophilic syndrome: new insights. Clin Res Cardiol 2010;99:419-27.

51. Massussi M, Scotti A, Lip GYH, et al. Left ventricular thrombosis: new perspectives on an old problem. Eur Heart J Cardiovasc Pharmacother 2020. [Epub ahead of print]. doi: 10.1093/ehjcvp/pvaa066.
52. Ibanez B, James S, Agewall S, et al. 2017 ESC guidelines for the management of acute myocardial infarction in patients presenting with ST-segment elevation: the task force for the management of acute myocardial infarction in patients presenting with ST-segment elevation of the European Society of Cardiology (ESC). Eur Heart J 2018;39:119-77.

53. Shaw LJ. Impact of contrast echocardiography on diagnostic algorithms: pharmacoeconomic implications. Clin Cardiol 1997;20:139-48.

54. Swinburn J, Lahiri A, Senior R. Tissue harmonic imaging: a new method for predicting left ventricular thrombus? J Am Soc Echocardiogr 2000;13:680-1.

55. Roifman I, Connelly KA, Wright GA. Echocardiography vs. cardiac magnetic resonance imaging for the diagnosis of left ventricular thrombus: a systematic review. Can J Cardiol 2015;31:785-91.

56. Vaidya VR, Prueksaritanond S, Bois JP, et al. Impact of acute left ventricular apical thrombus on cardioversion for atrial fibrillation. Echocardiography 2017;34:1708-11.

57. Barkhausen J, Hunold P, Eggebrecht H, et al. Detection and characterization of intracardiac thrombi on MR imaging. AJR Am J Roentgenol 2002;179:1539-44.

58. Mollet NR, Dymarkowski S, Volders W, et al. Visualization of ventricular thrombi with contrast-enhanced magnetic resonance imaging in patients with ischemic heart disease. Circulation 2002;106:2873-6.

59. Tomoda H, Hoshiai M, Furuya H, et al. Evaluation of left ventricular thrombus with computed tomography. Am J Cardiol 1981;48:573-7.

60. Rinuncini M, Zuin M, Scaranello F, et al. Differentiation of cardiac thrombus from cardiac tumor combining cardiac MRI and 18F-FDG-PET/CT Imaging. Int J Cardiol 2016;212:94-6.

61. Ouchi K, Nakamura F, Ikutomi M, et al. Usefulness of contrast computed tomography to detect left ventricular apical thrombus associated with takotsubo cardiomyopathy. Heart Vessels 2016;31:822-7.

62. Scheffel H, Baumueller S, Stolzmann P, et al. Atrial myxomas and thrombi: comparison of imaging features on CT. AJR Am J Roentgenol 2009;192:639-45.

63. Kassop D, Donovan MS, Cheezum MK, et al. Cardiac masses on cardiac CT: a review. Curr Cardiovasc Imaging Rep 2014;7:9281.

64. Vaitkus PT, Barnathan ES. Embolic potential, prevention and management of mural thrombus complicating anterior myocardial infarction: a meta-analysis. J Am Coll Cardiol 1993;22:1004-9. 
65. Maniwa N, Fujino M, Nakai M, et al. Anticoagulation combined with antiplatelet therapy in patients with left ventricular thrombus after first acute myocardial infarction. Eur Heart J 2018;39:201-8.

66. Merkler AE, Alakbarli J, Gialdini G, et al. Short-term risk of ischemic stroke after detection of left ventricular thrombus on cardiac magnetic resonance imaging. J Stroke Cerebrovasc Dis 2019;28:1027-31.

67. Leow AS, Sia CH, Tan BY, et al. Characterisation of acute ischemic stroke in patients with left ventricular thrombi after myocardial infarction. J Thromb Thrombolysis 2019;48:158-66.

68. Visser CA, Kan G, Meltzer RS, et al. Embolic potential of left ventricular thrombus after myocardial infarction: a two-dimensional echocardiographic study of 119 patients. J Am Coll Cardiol 1985;5:1276-80.

69. Stratton JR, Resnick AD. Increased embolic risk in patients with left ventricular thrombi. Circulation 1987;75:1004-11.

70. Haugland JM, Asinger RW, Mikell FL, et al. Embolic potential of left ventricular thrombi detected by twodimensional echocardiography. Circulation 1984;70:588-98.

71. Johannessen KA, Nordrehaug JE, von der Lippe G, et al. Risk factors for embolisation in patients with left ventricular thrombi and acute myocardial infarction. $\mathrm{Br}$ Heart J 1988;60:104-10.

72. Cullen JG, Korcuska K, Musser G, et al. Calcified left ventricular thrombus causing repeated retinal arterial emboli: clinical, echocardiographic, and pathologic features. Chest 1981;79:708-10.

73. Robinson AA, Trankle CR, Eubanks G, et al. Off-label use of direct oral anticoagulants compared with warfarin for left ventricular thrombi. JAMA Cardiol 2020;5:685-92.

74. Lattuca B, Bouziri N, Kerneis M, et al. Antithrombotic therapy for patients with left ventricular mural thrombus. J Am Coll Cardiol 2020;75:1676-85.

75. Bangalore S, Petre L, Herweg B, et al. Cardioversion in patients with left ventricular thrombus is not associated with increased thromboembolic risk. J Am Soc Echocardiogr 2006;19:438-40.

76. Rao HB, Yu R, Chitnis N, et al. Ventricular tachycardia ablation in the presence of left ventricular thrombus: safety and efficacy. J Cardiovasc Electrophysiol 2016;27:453-9.

77. Arvan S, Boscha K. Prophylactic anticoagulation for left ventricular thrombi after acute myocardial infarction: a prospective randomized trial. Am Heart J 1987;113:688-93.

78. Tavazzi L, Rovelli F, Serneri GN, et al. Randomised controlled trial of subcutaneous calcium-heparin in acute myocardial infarction. Lancet 1989;2:182-6.

79. Turpie AG, Robinson JG, Doyle DJ, et al. Comparison of high-dose with low-dose subcutaneous heparin to prevent left ventricular mural thrombosis in patients with acute transmural anterior myocardial infarction. N Engl J Med 1989;320:352-7.

80. Kouvaras G, Chronopoulos G, Soufras G, et al. The effects of long-term antithrombotic treatment on left ventricular thrombi in patients after an acute myocardial infarction. Am Heart J 1990;119:73-8.

81. Kontny F, Dale J, Abildgaard U, et al. Adverse effect of warfarin in acute myocardial infarction: increased left ventricular thrombus formation in patients not treated with high-dose heparin. Eur Heart J 1993;14:1040-3.

82. Kontny F, Dale J, Abildgaard U, et al. Randomized trial of low molecular weight heparin (dalteparin) in prevention of left ventricular thrombus formation and arterial embolism after acute anterior myocardial infarction: the Fragmin in Acute Myocardial Infarction (FRAMI) Study. J Am Coll Cardiol 1997;30:962-9.

83. Meurin P, Tabet JY, Renaud N, et al. Treatment of left ventricular thrombi with a low molecular weight heparin. Int J Cardiol 2005;98:319-23.

84. Le May MR, Acharya S, Wells GA, et al. Prophylactic warfarin therapy after primary percutaneous coronary intervention for anterior ST-segment elevation myocardial infarction. JACC Cardiovasc Interv 2015;8:155-62.

85. White DC, Grines CL, Grines LL, et al. Comparison of the usefulness of enoxaparin versus warfarin for prevention of left ventricular mural thrombus after anterior wall acute myocardial infarction. Am J Cardiol 2015;115:1200-3.

86. Smetana KS, Dunne J, Parrott K, et al. Oral factor Xa inhibitors for the treatment of left ventricular thrombus: a case series. J Thromb Thrombolysis 2017;44:519-24.

87. Robinson A, Ruth B, Dent J. Direct oral anticoagulants compared to warfarin for left ventricular thrombi: a single center experience. J Am Coll Cardiol 2018;71:A981.

88. Altıntaş B, Altındağ R, Bilge Ö, et al. The effect of ticagrelor based dual antiplatelet therapy on development of late left ventricular thrombus after acute anterior ST elevation myocardial infarction. Int J Cardiol 2019;287:19-26.

89. Daher J, Da Costa A, Hilaire C, et al. Management of left ventricular thrombi with direct oral anticoagulants: retrospective comparative study with vitamin $\mathrm{K}$ antagonists. Clin Drug Investig 2020;40:343-53.

90. Guddeti RR, Anwar M, Walters RW, et al. Treatment of 
left ventricular thrombus with direct oral anticoagulants: a retrospective observational study. Am J Med 2020;133:1488-91.

91. Iqbal H, Straw S, Craven TP, et al. Direct oral anticoagulants compared to vitamin $\mathrm{K}$ antagonist for the management of left ventricular thrombus. ESC Heart Fail 2020;7:2032-41.

92. Ali Z, Isom N, Dalia T, et al. Direct oral anticoagulant use in left ventricular thrombus. Thromb J 2020;18:29.

93. Guyatt GH, Akl EA, Crowther M. Executive summary: antithrombotic therapy and prevention of thrombosis, 9th ed: American College of Chest Physicians evidence-based clinical practice guidelines. Chest 2012;141:7S-47S.

94. O'Gara PT, Kushner FG, Ascheim DD, et al. 2013 ACCF/ AHA guideline for the management of ST-elevation myocardial infarction: a report of the American College of Cardiology Foundation/American Heart Association Task Force on Practice Guidelines. J Am Coll Cardiol 2013;61:e78-140.

95. JCS Joint Working Group. Guidelines for pharmacotherapy of atrial fibrillation (JCS 2013). Circ J 2014;78:1997-2021.

96. Ebrahimi M, Fazlinezhad A, Alvandi-Azari M. Longterm clinical outcomes of the left ventricular thrombus in patients with ST elevation anterior myocardial infarction. ARYA Atheroscler 2015;11:1-4.

97. Turgay Yildirim Ö, Akşit E, Aydin F, et al. Efficacy of direct oral anticoagulants on left ventricular thrombus. Blood Coagul Fibrinolysis 2019;30:96-103.

98. Keita I, Aubin-Auger I, Lalanne C, et al. Assessment of quality of life, satisfaction with anticoagulation therapy, and adherence to treatment in patients receiving longcourse vitamin $\mathrm{K}$ antagonists or direct oral anticoagulants for venous thromboembolism. Patient Prefer Adherence 2017;11:1625-34.

99. Lip GY, Hammerstingl C, Marin F, et al. Left atrial thrombus resolution in atrial fibrillation or flutter: results of a prospective study with rivaroxaban (X-TRA) and a retrospective observational registry providing baseline data (CLOT-AF). Am Heart J 2016;178:126-34.

100. Leow AS, Sia CH, Tan BY, et al. A meta-summary of case reports of non-vitamin $\mathrm{K}$ antagonist oral anticoagulant use in patients with left ventricular thrombus. J Thromb Thrombolysis 2018;46:68-73.

101. Yassin AS, Abubakar H, Mishra T, et al. Rivaroxaban for left ventricular thrombus. Am J Ther 2019;26:e511-5. 102. Cochran JM, Jia X, Hamzeh I, et al. Direct oral anticoagulant use for left ventricular thrombus: a single center experience. Circulation 2018;138:A16411.

103.McCarthy CP, Murphy S, Venkateswaran RV, et al. Left ventricular thrombus: contemporary etiologies, treatment strategies, and outcomes. J Am Coll Cardiol 2019;73:2007-9.

104. Fleddermann AM, Hayes CH, Magalski A, et al. Efficacy of direct acting oral anticoagulants in treatment of left ventricular thrombus. Am J Cardiol 2019;124:367-72.

105. Furie KL, Kasner SE, Adams RJ, et al. Guidelines for the prevention of stroke in patients with stroke or transient ischemic attack: a guideline for healthcare professionals from the American Heart Association/American Stroke Association. Stroke 2011;42:227-76.

106. Bolcal C, Kadan M, Kubat E, et al. Surgical treatment of a left ventricular apical thrombus via robotic surgery. J Card Surg 2019;34:216-8.

107.Zhao HJ, Zheng ZT, Wang ZH, et al. "Triple therapy" rather than "triple threat": a meta-analysis of the two antithrombotic regimens after stent implantation in patients receiving long-term oral anticoagulant treatment. Chest 2011;139:260-70.

108. Teklay G, Shiferaw N, Legesse B, et al. Drug-drug interactions and risk of bleeding among inpatients on warfarin therapy: a prospective observational study. Thromb J 2014;12:20.

109. Rogacka R, Chieffo A, Michev I, et al. Dual antiplatelet therapy after percutaneous coronary intervention with stent implantations in patients taking chronic oral anticoagulation JACC Cardiovasc Interv 2008;1:56-61.

110.Porter A, Konstantino Y, Iakobishvili Z, et al. Short-term triple therapy with aspirin, warfarin, and a thienopyridine among patients undergoing percutaneous coronary intervention. Catheter Cardiovasc Interv 2006;68:56-61.

111. Belliveau D, Quraishi A, Stewart R. Cardioembolic and bleeding outcomes of patients treated for left ventricular thrombus following primary percutaneous intervention for ST-elevation myocardial infarction. Can J Cardiol 2019;35:S108-9.

112. Gibson CM, Mehran R, Bode C, et al. Prevention of bleeding in patients with atrial fibrillation undergoing PCI. N Engl J Med 2016;375:2423-34.

113. Cannon CP, Bhatt DL, Oldgren J, et al. Dual antithrombotic therapy with dabigatran after PCI in atrial fibrillation. N Engl J Med 2017;377:1513-24.

114.Lopes RD, Heizer G, Aronson R, et al. Antithrombotic therapy after acute coronary syndrome or PCI in atrial 
fibrillation. N Engl J Med 2019;380:1509-24.

115.He J, Ge H, Dong JX, et al. Rationale and design of a prospective multi-center randomized trial of EARLY

treatment by rivaroxaban versus warfarin in ST-segment elevation MYOcardial infarction with Left Ventricular Thrombus (EARLY-MYO-LVT trial). Ann Transl Med 2020;8:392.

Cite this article as: Cruz Rodriguez JB, Okajima K, Greenberg BH. Management of left ventricular thrombus: a narrative review. Ann Transl Med 2021;9(6):520. doi: 10.21037/ atm-20-7839 